\title{
Epidermal growth factor receptor (EGFR) mutation and personalized therapy in advanced nonsmall cell lung cancer (NSCLC)
}

\author{
Kunihiko Kobayashi • Koichi Hagiwara
}

Received: 13 September 2012 / Accepted: 7 January 2013 /Published online: 30 January 2013

(C) The Author(s) 2013. This article is published with open access at Springerlink.com

\begin{abstract}
Before 2009, nonsmall cell lung cancer (NSCLC) was one disease entity treated by cytotoxic chemotherapy that provided a response rate of $20-35 \%$ and a median survival time (MST) of 10-12 months. In 2004, it was found that activated mutations of the epidermal growth factor receptor $(E G F R)$ gene were present in a subset of NSCLC and that tumors with EGFR mutations were highly sensitive to EGFR tyrosine kinase inhibitors (TKI). Four phase III studies (North East Japan (NEJ) 002, West Japan Thoracic Oncology Group (WJTOG) 3405, OPTIMAL, and EUROTAC) prospectively compared TKI (gefitinib or erlotinib) with cytotoxic chemotherapy as first-line therapy in EGFR-mutated NSCLC. These studies confirmed that progression-free survival (PFS) with TKIs (as the primary endpoint) was significantly longer than that with standard chemotherapy (hazard ratio $[\mathrm{HR}]=0.16-$ 0.49 ) from 2009 to 2011. Although the NEJ 002 study showed identical overall survival (OS) between the arms $(\mathrm{HR}=0.89)$, quality of life (QoL) was maintained much longer in patients treated with gefitinib. In conclusion, TKI should be considered as the standard first-line therapy in advanced EGFRmutated NSCLC. Since 2009, a new step has been introduced in the treatment algorithm for advanced NSCLC.
\end{abstract}

Keywords Nonsmall cell lung cancer (NSCLC) $\cdot E G F R$ mutation $\cdot$ EGFR-TKI $\cdot$ Gefitinib $\cdot$ Erlotinib

\section{Introduction}

Recent sequencing of DNA to identify polymorphisms has catalyzed the quest for protein kinase "driver" mutations,

K. Kobayashi $(\bowtie) \cdot$ K. Hagiwara

Saitama Medical University, Moroyama, Japan

e-mail: kobakuni@saitama-med.ac.jp which contribute to the transformation of a normal cell to a proliferating cancerous cell. On the other hand, kinase "passenger" mutations are considered to reflect mutations that merely build up in the course of cancerous cell replication and proliferation. At present, there are driver mutations in nonsmall cell lung cancer (NSCLC), such as epidermal growth factor receptor (EGFR) mutations [1-3], a fusion gene between echinoderm microtubule-associated protein-like 4 (EML4) and the anaplastic lymphoma kinase $(A L K)[4,5]$, and fusion genes with RET proto-oncogene (RET) [6-8], for which specific agents have been developed. In this manuscript, a road to personalized therapy by EGFR mutations in advanced NSCLC, which was the first experience to treat advanced NSCLC patients individually, is reviewed.

\section{Personalized therapy by $E G F R$ mutations in advanced NSCLC}

Dysregulation of protein kinases is frequently observed in cancer cells; therefore, protein kinases are attractive targets in the development of anticancer drugs. Small molecule inhibitors that block binding of adenosine-5'-triphosphate (ATP) to the tyrosine kinase catalytic domain have been developed, and gefitinib and erlotinib are the first generation of such agents, which act as tyrosine kinase inhibitors (TKI) at the EGFR. In 2004, three groups of researchers reported that activating mutations of $E G F R$ detected by direct sequencing were present in a subset of NSCLC and that tumors with EGFR mutations were highly sensitive to EGFR-TKI [1-3].

Although this knowledge is the first evidence for division of subpopulations in NSCLC and of the possibility of treating NSCLC patients individually, there have been two streams of clinical studies. Clinical efficacy of EGFR-TKIs such as gefitinib or erlotinib has been investigated initially 
in unselected patients [9-13] and, subsequently, on the basis of clinical characteristics [14]. On the other hand, in order to develop personalized therapy in NSCLC, clinical efficacy of EGFR-TKIs has been indicated by molecular selection in phase 3 trials of NSCLC (Table 1) [15-19].

\section{Unselected patients}

In the BR.21 phase III comparative study [9], 731 previously treated NSCLC patients (unselected by EGFR mutations) were allocated randomly to the erlotinib or placebo groups at a ratio of 2:1. At the primary endpoints, erlotinib was significantly superior in terms of both progression-free survival (PFS) (2.2 months vs. 1.8 months, respectively, hazard ratio $(\mathrm{HR})=0.61, p<0.001)$ and median survival time (MST) $(6.7$ months vs. 4.7 months, respectively, $\mathrm{HR}=$ $0.70, p<0.001)$. On the basis of the results of BR.21, erlotinib has become a standard therapy for previously treated patients with advanced NSCLC and is now used in previously treated cases of NSCLC that may or may not have EGFR mutations.

In order to evaluate gefitinib, a phase III study (Iressa Survival Evaluation in Advanced Lung Cancer (ISEL)) was carried out [10]. A total of 1,692 patients refractory to or intolerant of their latest chemotherapy were randomized to receive either gefitinib $(250 \mathrm{mg} /$ day $)$ or placebo plus best supportive care (BSC). The primary endpoint, MST, was 5.1 months in the placebo group and 5.6 months in the gefitinib group, with no significant differences between the two groups $(p=0.087)$. Therefore, efficacy of gefitinib in NSCLC patients unselected by EGFR mutations was not indicated. Another randomized phase III study (INTEREST) [11] compared gefitinib with standard second-line chemotherapy using docetaxel in 1,433 previously treated NSCLC patients unselected by EGFR mutations. As to overall survival (OS), which was the primary endpoint of the study, the HR was 1.020 (95\% confidence interval [CI]: 0.905-1.150) and did not exceed the preset upper limit (1.154), thus endorsing

Table 1 Clinical studies using EGFR-TKI

\begin{tabular}{lll}
\hline & $\begin{array}{l}\text { Second-line } \\
\text { treatment }\end{array}$ & First-line treatment \\
\hline Unselected patients & $\begin{array}{l}\text { BR.21 } \\
\text { ISEL } \\
\text { INTEREST }\end{array}$ & \\
& V-15-32 & \\
& & IPASS \\
$\begin{array}{c}\text { Selection by } \\
\text { background }\end{array}$ & NEJ Gefitinib Study-02 \\
$\begin{array}{c}\text { Selection by EGFR } \\
\text { mutation }\end{array}$ & & WJTOG 3405 \\
& & OPTIMAL (CTONG 0802) \\
& & EURTAC-SLCG GECP06/01 \\
\end{tabular}

the noninferiority of gefitinib to docetaxel. However, the V15-32 randomized phase III study, which aimed to confirm the noninferiority of gefitinib to docetaxel in regard to OS [12], was carried out in Japan and involved 490 previously treated NSCLC patients unselected by EGFR mutations. MST were 14.0 and 11.5 months for the gefitinib and docetaxel groups, respectively, and the HR was 1.12 (95\% CI: 0.89-1.40). Thus, the study did not demonstrate noninferiority of gefitinib to docetaxel. The potency of gefitinib in unselected patients with NSCLC is considered to be controversial.

\section{Selection by background}

In preplanned subgroup analyses of the ISEL trial mentioned above [20], gefitinib was shown to extend survival in Asian patients (MST: 9.5 months vs. 5.5 months, HR= $0.66, p=0.01)$. In addition, covariate analyses of demographic subsets among patients of Asian origin treated with gefitinib showed a survival advantage $(\mathrm{HR}<1)$ across neversmokers (HR, 0.37; $p=0.0004)$ and adenocarcinoma patients (HR, 0.54; $p=0.0028$ ). Therefore, in March 2006, the Iressa ${ }^{\circledR}$ Pan-Asia Study (IPASS) was initiated to investigate the effectiveness of first-line gefitinib in previously untreated patients in East Asia who had advanced pulmonary adenocarcinoma and who were light or nonsmokers [14]. The IPASS included 1,217 NSCLC patients selected by backgrounds and compared gefitinib therapy with carboplatin (CBDCA)+ paclitaxel (PTX) therapy as a first-line treatment. As to PFS, which was the primary endpoint of this study, the HR was 0.741 (95\% CI: 0.651-0.845), and it was reported that the outcome was significantly better in the gefitinib group. However, since the survival curves for the two groups crossed each other, it was difficult to interpret the value of HR (Fig. 1a). Because Cox analysis should be used in cases having a constant relationship between HR and time [21], this could not be used when the curves crossed each other. For example, PFS of gefitinib was better, the same, or worse than that of CDBCA+PTX at 12,6 , or 3 months, respectively (Fig. 1a).

Although the result at the primary endpoint in the IPASS was inconclusive, the importance of the IPASS report is demonstrated in its subset analyses [14]. Among 1,217 patients enrolled, an EGFR mutation test (amplification mutation refractory system) was performed on tumor samples from 437 patients (36\%). In this analysis, the crossing of the survival curves seen in Fig. 1a disappeared (Fig. 1b, c). In the subgroup of 261 patients who were positive for $E G F R$ mutation, PFS was significantly longer among those who received gefitinib than among those who received CBDCA-PTX (HR $=0.48 ; P<0.001)$, whereas in the subgroup of 176 patients who were negative for the mutation, PFS was significantly longer among those who received CBDCA-PTX $(\mathrm{HR}=2.85 ; P<0.001)$. Thus, the critical 


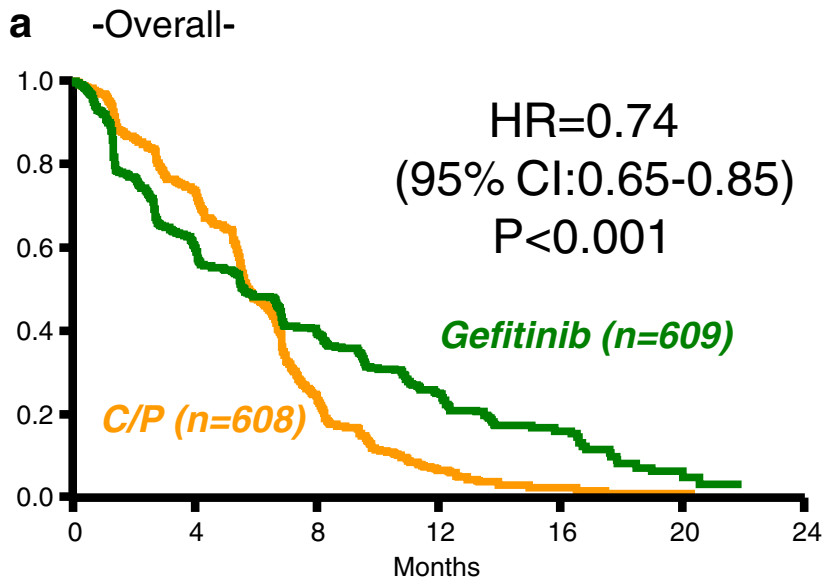

Fig. 1 Progression-free survival in IPASS. a Kaplan-Meier curves of PFS for Asian patients treated with gefitinib or carboplatin plus paclitaxel who had pulmonary adenocarcinoma and who were light or

message was that there was no indication for gefitinib in patients who were negative for the $E G F R$ mutation.

In addition to the $E G F R$ mutation test described above, the biomarkers analyzed in IPASS were EGFR gene copy number (fluorescent in situ hybridization (FISH)), and EGFR protein expression (immunohistochemistry) [22]. PFS was significantly longer with gefitinib in patients whose tumors had both high EGFR gene copy number and $E G F R$ mutation (HR, 0.48) but was significantly shorter when a high $E G F R$ gene copy number was not accompanied by EGFR mutation (HR, 3.85) (Fig. 2). Among the three biomarkers, EGFR mutations are the strongest predictive biomarker for PFS and tumor response to first-line gefitinib vs. CBDCA+PTX. Selection by backgrounds, Asian origin, adenocarcinoma histology, and light or nonsmoking resulted in an EGFR mutation-rich population at a rate of $60 \%(261$ EGFR-mutated patients/437 patients evaluated). Thus, if the strategy of selection by backgrounds is employed, there should be a $40 \%$ risk associated with TKI treatment for patients without $E G F R$ mutations.
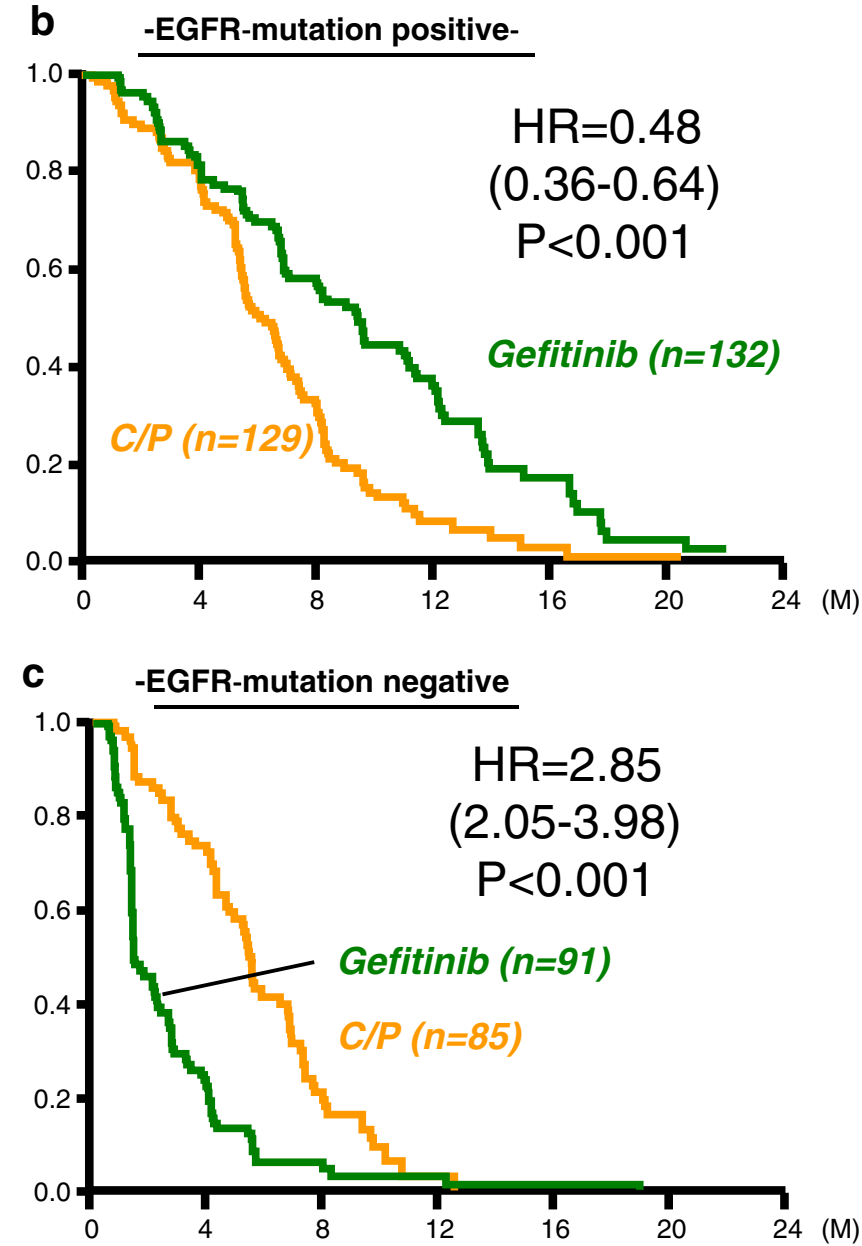

nonsmokers. b and $\mathbf{c}$ show PFS for patients with or without $E G F R$ mutations treated with gefitinib or carboplatin plus paclitaxel, respectively, in subset analyses. [14]

Selection by EGFR mutations

Since 2004 when the pivotal studies reported on the relationship between EGFR mutations and TKI sensitivity, multiple phase II studies have confirmed a striking response to EGFRTKIs in this population in Japan [23-29]. A combined analysis employing these phase II studies, named IRESSA Combined Analysis of the Mutation Positives (I-CAMP) study, indicated longer PFS with gefitinib than with standard chemotherapy [30]. In March 2006, at the same time that the IPASS study started, two phase III trials, the North East Japan (NEJ) 002 study and the West Japan Thoracic Oncology Group (WJTOG) 3405 [16, 17], were initiated, which compared gefitinib with standard chemotherapy in first-line treatment for EGFR-mutated NSCLC (Table 2). NEJ 002 first confirmed as the primary endpoint that PFS in the gefitinib group was significantly longer than that in the CBDCA plus PTX group (10.8 months vs. 5.4 months, $\mathrm{HR}=0.30, P<0.001$ ) $[15,16]$. In WJTOG3405, the gefitinib group also had significantly longer PFS compared with the cisplatin plus docetaxel 
Hazard ratio (gefitinib : carboplatin / paclitaxel) and 95\% Cl

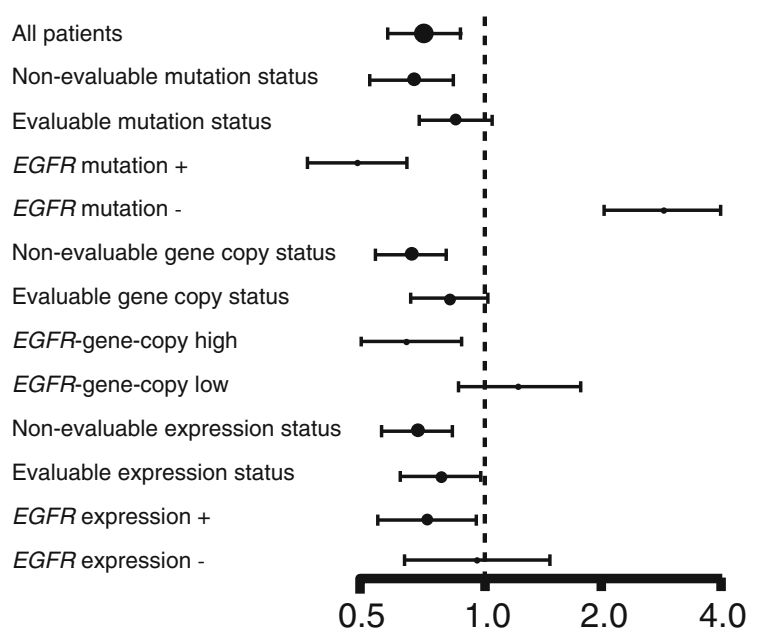

Favours gefitinib Favours C / P

Fig. 2 Biomarker for gefitinib. In comparing $E G F R$ mutation, $E G F R$ gene copy number, and EGFR expression status, EGFR mutation is the best biomarker for gefitinib. [22]

goup, with a median PFS of 9.2 months vs. 6.3 months (HR $0.489, p<0.0001$ ) [17]. In order to evaluate erlotinib further, the phase III OPTIMAL study [18] was initiated in August 2008. It compared the PFS of erlotinib with gemcitabine plus CBDCA in the first-line treatment of Chinese patients with advanced EGFR mutation-positive NSCLC. The median PFS was significantly longer in erlotinib-treated patients than in those on chemotherapy (13.1 vs. 4.6 months; $\mathrm{HR}=0.16$; $p<0.0001)$. In another phase III study, EURTAC [19], started in February 2007, PFS with erlotinib was compared with standard chemotherapy for first-line treatment of European patients with advanced EGFR mutation-positive NSCLC. The preplanned interim analysis showed that the median PFS was 9.7 months in the erlotinib group, compared with
5.2 months in the standard chemotherapy group $(\mathrm{HR}=0.37$; $p<0.0001)$.

OS was retrospectively compared between advanced NSCLC patients with sensitive EGFR mutations who began first-line systemic therapy before and after gefitinib approval in Japan (January 1999-July 2001 and July 2002-December 2004, respectively) [31]. In 136 (41\%) of the 330 patients treated at the National Cancer Center Hospital of Japan, although no significant survival improvement was observed in patients without EGFR mutations (MST: 13.2 vs. 10.4 months, respectively; $P=0.13$ ), OS was significantly longer among the EGFR-mutant patients treated after gefitinib approval compared with the OS of patients treated before gefitinib approval (MST: 27.2 vs. 13.6 months, respectively; $P<0.001)$. However, a combined analysis of ICAMP and a post hoc analysis of IPASS suggested identical survival of patients on gefitinib and chemotherapy in first-line treatment for $E G F R$-mutated patients [30,32]. Furthermore, a secondary endpoint of both NEJ 002 [33] and WJTOG3405 [34] prospectively showed identical OS between gefitinib and chemotherapy in first-line treatment of NSCLC patients harboring sensitive EGFR mutations (Table 2), although OS data from OPTIMAL and EURTAC are immature at the present time. It must be explained that in almost all of the patients who were treated with first-line chemotherapy in NEJ 002 and WJTOG 3405 , a crossover treatment with gefitinib was undertaken. Therefore, from the viewpoint of OS, the effect of gefitinib is additive to that of chemotherapy, indicating that both first-line and second-line gefitinib are acceptable.

When OS is identical between two arms, improvement in quality of life (QoL) and disease-related symptoms are among the key goals in the treatment of NSCLC. IPASS reported better QoL in EGFR-mutated patients treated with gefitinib than in those treated with CBDCA+PTX, but this analysis was a post hoc estimation [35]. With the exception of WJTOG3405, the
Table 2 Phase III studies of TKI for $E G F R$-mutated patients

\begin{tabular}{|c|c|c|c|c|c|c|c|}
\hline \multirow[t]{9}{*}{ TKI for $E G F R$-mutated patients } & Trial & Arm & Number & $\mathrm{RR}$ & PFS & OS & Ref. \\
\hline & NEJ 002 & Gefitinib & 114 & $74 \%$ & $10.8 \mathrm{~m}$ & $27.7 \mathrm{~m}$ & NEJM (2010) \\
\hline & & CbPXL & 110 & $31 \%$ & $5.4 \mathrm{~m}$ & $26.6 \mathrm{~m}$ & OS: Ann Oncol. (in press) \\
\hline & & & & & $\mathrm{HR}=0.30^{*}$ & $\mathrm{HR}=0.89$ & QOL: Oncologist (2012) \\
\hline & WJTOG 3405 & Gefitinib & 86 & $62 \%$ & $9.2 \mathrm{~m}$ & $36 \mathrm{~m}$ & Lancet Oncol (2010) \\
\hline & & CisDTX & 86 & $32 \%$ & $\begin{array}{c}6.3 \mathrm{~m} \\
\mathrm{HR}=0.49^{*}\end{array}$ & $\begin{array}{l}39 \mathrm{~m} \\
\mathrm{HR}=1.19\end{array}$ & OS: ASCO (2012) \\
\hline & OPTIMAL & Erlotinib & 83 & $83 \%$ & $13.1 \mathrm{~m}$ & NR & Lancet Oncol (2011) \\
\hline & & CbGEM & 82 & $36 \%$ & $\begin{array}{c}4.6 \mathrm{~m} \\
\mathrm{HR}=0.16^{*}\end{array}$ & NR & QOL: ASCO (2012) \\
\hline & EURTAC & Erlotinib & 86 & $58 \%$ & $9.7 \mathrm{~m}$ & NR & Lancet Oncol (2012) \\
\hline *shows a significant difference & & Pt doublet & 87 & $15 \%$ & $\begin{array}{c}5.2 \mathrm{~m} \\
\mathrm{HR}=0.37^{*}\end{array}$ & NR & \\
\hline
\end{tabular}




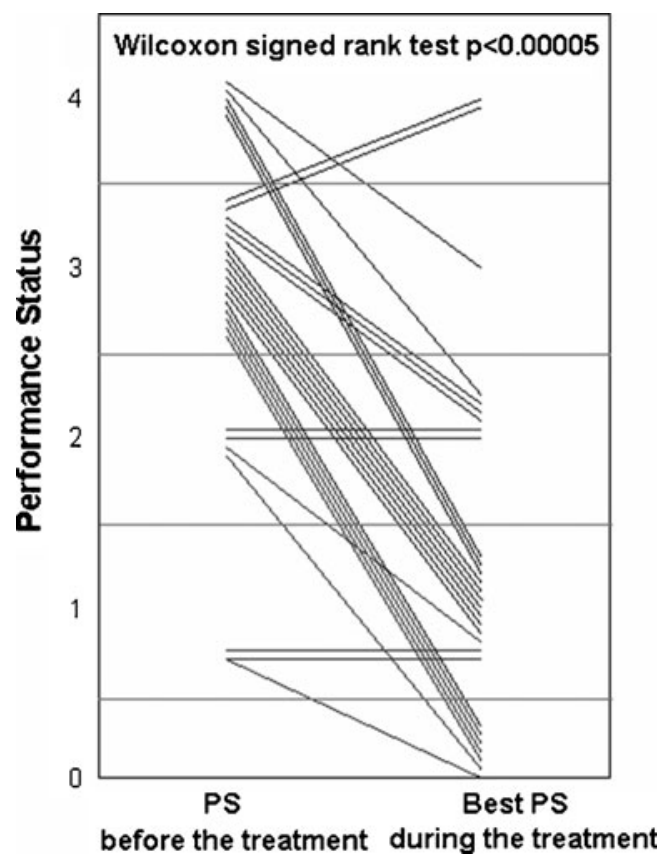

Fig. 3 Performance status (PS) improvement by gefitinib in the NEJ 001 Study. Each line shows changes of PS in a patient. [39]

other three trials listed in Table 2 prospectively investigated QoL of NSCLC patients with sensitive EGFR mutations who were treated with EGFR-TKI or standard chemotherapy, and NEJ 002 and OPTIMAL have presented the results [36, 37]. In NEJ 002, patients' QoL was assessed weekly using the Care Notebook [38], and the primary endpoint of the QoL analysis was time to deterioration from baseline on each of the physical, mental, and life well-being QoL scales. Kaplan-Meier probability curves and logrank tests showed that time to defined deterioration in physical and life well-being significantly favored gefitinib over chemotherapy ( $\mathrm{HR}=0.34 ; p<0.0001$ and HR, $0.43 ; p<0.0001$, respectively); this indicated that QoL was maintained much longer in patients treated with gefitinib than in those treated with standard chemotherapy [36]. In OPTIMAL, the Functional Assessment of Cancer Therapy (FACT) measuring system showed that compared with the gemcitabine/CBDCA group, the erlotinib group had a clinically relevant improvement in QoL, as assessed by scores on the FACT-L (73 \% vs. $29.6 \%$; odds ratio $(\mathrm{OR})=6.9 ; p<0.0001)$, the LCSS ( $75.7 \%$ vs. $31.5 \%$; OR=6.77; $p<0.0001)$, and the TOI (71.6 \% vs. $24.1 \%$; OR=7.79; $p<0.0001)$ [37]. These QoL results conclusively indicate that EGFR-TKI should be considered as the standard first-line therapy for advanced EGFR-mutated NSCLC despite the lack of survival advantage.

EGFR-TKIs for $E G F R$-mutated patients with poor performance status and advanced age

The multicenter phase II NEJ 001 study was undertaken to investigate the efficacy and feasibility of gefitinib treatment for advanced NSCLC patients harboring EGFR mutations but who were ineligible for chemotherapy due to poor performance status (PS) [39]. The overall response rate was $66 \%$, and median PFS and MST were 6.5 months and 17.8 months, respectively. PS improvement rate was $79 \%(p<0.00005)$; in particular, $68 \%$ of the 22 patients improved from PS $\geq 3$ at baseline to PS 0 or 1. (Fig. 3) Thus, the "Lazarus Response" was observed in treatment-naïve, poor PS patients with NSCLC and EGFR mutations [40]. In patients with sensitive EGFR mutations but with extremely poor PS (suspected MST less than 4 months with BSC), the difference in benefit with or without gefitinib treatment was so marked that a randomized phase III study to compare gefitinib to BSC alone may not be justified. This was the first occasion on which changes in treatment guidelines were provoked by a phase II study of NSCLC. Since previously there has been no standard treatment for these patients with short life expectancy other than BSC, examination of EGFR mutations as a biomarker is also strongly recommended in this patient population.

In regard to so-called "fit" elderly patients harboring EGFR mutations, the NEJ 003 phase II study [41] investigated patients with chemotherapy-naïve history, a median age of 80 years (range: $75-87$ years), and PS $0-1$, who were treated with gefitinib as a first-line treatment. The response rate was $74 \%$, and the median PFS and OS were 12.3 months and 33.8 months, respectively. Considering its strong antitumor activity and mild toxicity, first-line gefitinib may be preferable to standard chemotherapy in this population. However, a phase III study comparing gefitinib to standard chemotherapy may be needed to provide the final evidence of benefit in advanced EGFR-mutated "fit" elderly patients.

Tarceva Lung cancer Survival Treatment (TRUST) [42] was an open-label, phase IV study of unselected patients with advanced NSCLC. In a subpopulation of elderly patients ( $\geq 70$ years) receiving first-line erlotinib $(n=485)$ in TRUST [43], the disease control rate was $79 \%$, median PFS was 4.57 months, and MST was 7.29 months. A total of 87 subpopulation patients $(18 \%)$ had an erlotinib-related adverse event (AE); $4 \%$ had a $\geq 3$ grade erlotinib-related AE. Erlotinib was effective and well-tolerated and may be considered for unselected, elderly patients with advanced NSCLC who are unsuitable for standard first-line chemotherapy or radiotherapy. However, there have been few prospective studies of erlotinib in advanced, EGFR-mutated, "fit" elderly patients.

\section{EGFR mutation tests}

Direct sequencing of $E G F R$ requires histology obtained by operation. The NEJ 001, NEJ 002, and NEJ 003 series all used the same EGFR mutation test, the peptide nucleic acid-locked nucleic acid polymerase chain reaction clamp (PNA LNA PCR clamp) [44-46]. This is 
a technological innovation that can make not only tissue-based assessment but also cytology-based assessment of EGFR mutations. Briefly, genomic DNA fragments surrounding mutation hot spots of the EGFR gene are amplified by PCR in the presence of a clamp primer synthesized from PNA with a wild-type sequence. This leads to preferential amplification of the mutant sequence, which is detected by a fluorescent primer that incorporates LNA to increase specificity. As a result, a mutant EGFR sequence is detected in the presence of a 100 -fold wild-type sequence. Thus, by the PNA LNA PCR clamp, a small number of EGFR mutation-positive cancer cells are detected within $3 \mathrm{~h}$. The sensitivity and specificity of the PNA-LNA PCR clamp were $97 \%$ and $100 \%$, respectively [46]. Therefore, EGFR testing by the PNA LNA PCR clamp was possible in patients with extremely poor PS and of advanced age.

In 2012, the performance, sensitivity, and concordance among five $E G F R$ tests of PCR-Invader ${ }^{\circledR}$, PNA LNA PCR clamp, direct sequencing, Cycleave ${ }^{\mathrm{TM}}$, and Scorpion Amplification Refractory Mutation System (ARMS) ${ }^{\circledR}$ were reported [47]. All tests, except direct sequencing, detected mutation types at $\geq 1 \%$ mutant DNA. Analysis success rates were $91.4-100 \%$, and interassay concordance rates of successfully analyzed samples were $94.3-100 \%$. It was concluded that cytology-derived DNA is a viable alternative to formalin-fixed paraffin-embedded (FFPE) tissue samples for analyzing $E G F R$ mutations.

It was clarified that frequencies of $E G F R$-mutated NSCLC patients are approximately $31 \%$ and $16.6 \%$ in Japan and Europe, respectively [46, 48]. In Japan, approximately 50,000 patients were newly diagnosed as NSCLC in 1 year. In 2011, approximately 48,000 tests for EGFR mutations were carried out under national health insurance, indicating that most patients with NSCLC were screened in Japan. Under circumstances where EGFR mutations, $E M L 4-A L K$ fusion gene, and RET fusion genes should be tested, routine screening for all of these will be required when making diagnosis of NSCLC.

Conflict of interest Koichi Hagiwara received consulting fee or honorarium from AstraZeneca and received payment for patent for EGFR test method. Kunihiko Kobayashi has been paid for conducting lectures by Taiho, AstraZeneca, and Chugai.

Open AccessThis article is distributed under the terms of the Creative Commons Attribution License which permits any use, distribution, and reproduction in any medium, provided the original author(s) and the source are credited.

\section{References}

1. Lynch TJ, Bell DW, Sordella R et al (2004) Activating mutations in the epidermal growth factor receptor underlying responsiveness of nonsmall-cell lung cancer to gefitinib. N Engl J Med 350(21):2129-2139
2. Paez JG, Janne PA, Lee JC et al (2004) EGFR mutations in lung cancer: correlation with clinical response to gefitinib therapy. Science 304(5676): 1497-1500

3. Pao W, Miller V, Zakowski M et al (2004) EGF receptor gene mutations are common in lung cancers from "never smokers" and are associated with sensitivity of tumors to gefitinib and erlotinib. Proc Natl Acad Sci U S A 101(36):13306-13311

4. Soda M, Choi YL, Enomoto M et al (2007) Identification of the transforming EML4-ALK fusion gene in non-small-cell lung cancer. Nature 448(7153):561-566

5. Kwak EL, Bang YJ, Camidge DR et al (2010) Anaplastic lymphoma kinase inhibition in non-small-cell lung cancer. N Engl J Med 363:1693-1703

6. Kohno T, Ichikawa H, Totoki Y, Yasuda K, Hiramoto M, Nammo T, Sakamoto H, Tsuta K, Furuta K, Shimada Y, Iwakawa R, Ogiwara H, Oike T, Enari M, Schetter AJ, Okayama H, Haugen A, Skaug V, Chiku S, Yamanaka I, Arai Y, Watanabe S, Sekine I, Ogawa S, Harris CC, Tsuda H, Yoshida T, Yokota J, Shibata T (2012) KIF5B-RET fusions in lung adenocarcinoma. Nat Med 18(3):375-377

7. Takeuchi K, Soda M, Togashi Y, Suzuki R, Sakata S, Hatano S, Asaka R, Hamanaka W, Ninomiya H, Uehara H, Lim Choi Y, Satoh Y, Okumura S, Nakagawa K, Mano H, Ishikawa Y (2012) RET, ROS1 and ALK fusions in lung cancer. Nat Med 18(3):378381

8. Lipson D, Capelletti M, Yelensky R, Otto G, Parker A, Jarosz M, Curran JA, Balasubramanian S, Bloom T, Brennan KW, Donahue A, Downing SR, Frampton GM, Garcia L, Juhn F, Mitchell KC, White E, White J, Zwirko Z, Peretz T, Nechushtan H, SoussanGutman L, Kim J, Sasaki H, Kim HR, Park SI, Ercan D, Sheehan CE, Ross JS, Cronin MT, Jänne PA, Stephens PJ (2012) Identification of new ALK and RET gene fusions from colorectal and lung cancer biopsies. Nat Med 18(3):382-384

9. Shepherd FA, Rodrigues Pereira J et al (2005) Erlotinib in previously treated non-small-cell lung cancer. N Engl J Med 353 (2):123-132

10. Thatcher N, Chang A, Parikh P et al (2005) Gefitinib plus best supportive care in previously treated patients with refractory advanced non-small-cell lung cancer: results from a randomised, placebocontrolled, multicentre study (Iressa Survival Evaluation in Lung Cancer). Lancet 366:1527-1537

11. Kim ES, Hirsh V, Mok T et al (2008) Gefitinib versus docetaxel in previously treated non-small-cell lung cancer (INTEREST): a randomised phase 3 trial. Lancet 372(9652):1809-1818

12. Maruyama R, Nishiwaki Y, Tamura T et al (2008) Phase III study, $\mathrm{V}-15-32$, of gefitinib versus docetaxel in previously treated Japanese patients with non-small-cell lung cancer. J Clin Oncol 26(26):4244-4252

13. Lee DH, Park K, Kim JH et al (2010) Randomized phase III trial of gefitinib versus docetaxel in non-small cell lung cancer patients who have previously received platinum-based chemotherapy. Clin Cancer Res 16(4):1307-1314

14. Mok TS, Wu YL, Thongprasert S et al (2009) Gefitinib or carboplatin-paclitaxel in pulmonary adenocarcinoma. N Engl $\mathrm{J}$ Med 361(10):947-957

15. Kobayashi K, Inoue A, Maemondo M, et al (2009) First-line gefitinib versus first-line chemotherapy by carboplatin (CBDCA) plus paclitaxel (TXL) in non-small cell lung cancer (NSCLC) patients (pts) with EGFR mutations: a phase III study (002) by North East Japan Gefitinib Study Group. J Clin Oncol 27: Suppl:411s. abstract

16. Maemondo M, Inoue A, Kobayashi K et al (2010) Gefitinib or chemotherapy for non-small-cell lung cancer with mutated EGFR. N Engl J Med 362(25):2380-2388

17. Mitsudomi T, Morita S, Yatabe Y et al (2010) Gefitinib versus cisplatin plus docetaxel in patients with non-small-cell lung cancer harbouring mutations of the epidermal growth factor receptor 
(WJTOG3405): an open label, randomised phase 3 trial. Lancet Oncol 11(2):121-128

18. Zhou C, Wu YL, Chen G et al (2011) Erlotinib versus chemotherapy as first-line treatment for patients with advanced EGFR mutation-positive non-small-cell lung cancer (OPTIMAL, CTONG-0802): a multicentre, open-label, randomised, phase 3 study. Lancet Oncol 12:735-742

19. Rosell R, Carcereny E, Gervais R et al (2012) Erlotinib versus standard chemotherapy as first-line treatment for European patients with advanced EGFR mutation-positive non-small-cell lung cancer (EURTAC): a multicentre, open-label, randomised phase 3 trial. Lancet Oncol 13:239-246

20. Chang A, Parikh P, Thongprasert S et al (2006) Gefitinib (IRESSA) in patients of Asian origin with refractory advanced non-small cell lung cancer: subset analysis from the ISEL study. J Thorac Oncol 1(8):847-855

21. Cox DR (1972) Regression models and life-tables. J R Stat Soc Ser B Methodol 34(2):187-220

22. Fukuoka $\mathrm{M}, \mathrm{Wu} \mathrm{YL}$, Thongprasert S et al (2011) Biomarker analyses and final overall survival results from a phase III, randomized, openlabel, first-line study of gefitinib versus carboplatin/paclitaxel in clinically selected patients with advanced non-small-cell lung cancer in Asia (IPASS). J Clin Oncol 29(21):2866-2874

23. Inoue A, Suzuki T, Fukuhara T et al (2006) Prospective phase II study of gefitinib for chemotherapy-naive patients with advanced non-small-cell lung cancer with epidermal growth factor receptor gene mutations. J Clin Oncol 24:3340-3346

24. Asahina H, Yamazaki K, Kinoshita I et al (2006) A phase II trial of gefitinib as first-line therapy for advanced non-small cell lung cancer with epidermal growth factor receptor mutations. Br J Cancer 95:998-1004

25. Sutani A, Nagai Y, Udagawa K et al (2006) Gefitinib for nonsmall-cell lung cancer patients with epidermal growth factor receptor gene mutations screened by peptide nucleic acid-locked nucleic acid PCR clamp. Br J Cancer 95:1483-1489

26. Yoshida K, Yatabe Y, Park JY et al (2007) Prospective validation for prediction of gefitinib sensitivity by epidermal growth factor receptor gene mutation in patients with non-small cell lung cancer. J Thorac Oncol 2:22-28

27. Sunaga N, Tomizawa Y, Yanagitani N et al (2007) Phase II prospective study of the efficacy of gefitinib for the treatment of stage III/IV non-small cell lung cancer with EGFR mutations, irrespective of previous chemotherapy. Lung Cancer 56:383-389

28. Tamura K, Okamoto I, Kashii T et al (2008) Multicentre prospective phase II trial of gefitinib for advanced non-small cell lung cancer with epidermal growth factor receptor mutations: results of the West Japan Thoracic Oncology Group trial (WJTOG0403). Br J Cancer 98:907-914

29. Sugio K, Uramoto H, Onitsuka T, et al (2008) Prospective phase II study of gefitinib in non-small cell lung cancer with epidermal growth factor receptor gene mutations. Lung Cancer

30. Morita S, Okamoto I, Kobayashi K et al (2009) Combined survival analysis of prospective clinical trials of gefitinib for non-small cell lung cancer with EGFR mutations. Clin Cancer Res 15(13):44934498, Epub 2009 Jun 16

31. Takano T, Fukui T, Ohe $\mathrm{Y}$ et al (2008) EGFR mutations predict survival benefit from gefitinib in patients with advanced lung adenocarcinoma: a historical comparison of patients treated before and after gefitinib approval in Japan. J Clin Oncol 26:5589-5595

32. Yang CH, Fukuoka M, Mok TS et al (2010) Final overall survival results from a phase III: randomised, open-label, first-line study of gefitinib v carboplatin/paclitaxel in clinically selected patients with advanced non-small cell lung cancer in Asia (IPASS). Presented at ESMO 2010. Ann Oncol 21(Supplement 8):viii1viii12
33. Inoue A, Kobayashi K, Maemondo M, et al. Updated overall survival results from a randomized phase III trial comparing gefitinib with carboplatin-paclitaxel for chemo-naïve non-small 5 cell lung cancer with sensitive EGFR gene mutations (NEJ002). Ann Oncol (in press)

34. Mitsudomi T, Morita S, Yatabe Y, et al (2012) Updated overall survival results of WJTOG 3405, a randomized phase III trial comparing gefitinib with cisplatin plus docetaxel as the first-line treatment for patients with non-small cell lung cancer harboring mutations of the epidermal growth factor receptor (EGFR). J Clin Oncol 30, (suppl; ASCO 2012 abstr 7521)

35. Thongprasert S, Duffield E, Saijo N et al (2011) Health-related quality-of-life in a randomized phase III first-line study of gefitinib versus carboplatin/paclitaxel in clinically selected patients from Asia with advanced NSCLC (IPASS). J Thorac Oncol 6 (11): $1872-1880$

36. Oizumi S, Kobayashi K, Inoue A et al (2012) Quality of life with gefitinib in patients with EGFR-mutated non-small cell lung cancer: quality of life analysis of North East Japan Study Group 002 Trial. Oncologist 17(6):863-870

37. Zhou C, Wu YL, Chen G et al (2011) Updated efficacy and quality-of-life (QoL) analyses in OPTIMAL, a phase III, randomized, open-label study of first-line erlotinib versus gemcitabine/ carboplatin in patients with $E G F R$-activating mutation-positive (EGFR Act Mut+) advanced non-small cell lung cancer (NSCLC). J Clin Oncol 29 (suppl; ASCO 2011 abstr 7520)

38. Kobayashi K, Green J, Shimonagayoshi M et al (2005) Validation of the care notebook for measuring physical, mental and life wellbeing of patients with cancer. Qual Life Res 14(4):1035-1043

39. Inoue A, Kobayashi K, Usui K et al (2009) First-line gefitinib for patients with advanced non-small-cell lung cancer harboring epidermal growth factor receptor mutations without indication for chemotherapy. J Clin Oncol 27(9):1394-1400

40. Langer CJ (2009) The "lazarus response" in treatment-naive, poor performance status patients with non-small-cell lung cancer and epidermal growth factor receptor mutation. J Clin Oncol 27 (9):1350-1354

41. Maemondo M, Minegishi Y, Inoue A et al (2012) First-line gefitinib in patients aged 75 or older with advanced non-small cell lung cancer harboring epidermal growth factor receptor mutations: NEJ 003 Study. J Thorac Oncol 7(9):1417-1422

42. Reck M, van Zandwijk N, Gridelli C et al (2010) Erlotinib in advanced non-small cell lung cancer: efficacy and safety findings of the global phase IV Tarceva Lung Cancer Survival Treatment study. J Thorac Oncol 5(10):1616-1622

43. Merimsky O, Cheng CK, Au JS et al (2012) Efficacy and safety of first-line erlotinib in elderly patients with advanced non-small cell lung cancer. Oncol Rep 28(2):721-727

44. Nagai Y, Miyazawa H, Huqun et al (2005) Genetic heterogeneity of the epidermal growth factor receptor in non-small cell lung cancer cell lines revealed by a rapid and sensitive detection system, the peptide nucleic acid-locked nucleic acid PCR clamp. Cancer Res 65(16):7276-7282

45. Miyazawa H, Tanaka T, Nagai Y et al (2008) Peptide nucleic acidlocked nucleic acid polymerase chain reaction clamp-based detection test for gefitinib-refractory T790M epidermal growth factor receptor mutation. Cancer Sci 99(3):595-600

46. Tanaka T, Matsuoka M, Sutani A et al (2010) Frequency of and variables associated with the EGFR mutation and its subtypes. Int $\mathrm{J}$ Cancer 126(3):651-655

47. Goto K, Satouchi M, Ishii G, et al. An evaluation study of EGFR mutation tests utilized for non-small-cell lung cancer in the diagnostic setting. Ann Oncol. 2012;23(11):2914-2915

48. Rosell R, Moran T, Queralt C et al (2009) Screening for epidermal growth factor receptor mutations in lung cancer. N Engl J Med 361 (10):958-967 